\title{
Like the Blank Tile in Scrabble
}

\author{
Marek Zaleski
}




\section{Interpretations}

Marek Zaleski

\section{Like the Blank Tile in Scrabble}

DOI:10.18317/td.2018.en.1.8

The essay was made pos-

sible by an endowment

from the National Science

Center, decision no. DEC-

2011/03/B/HS2/05729.

Marek Zaleski -

Professor at the

Institute of Literary

fective turn" that has been the subject of interdisciplinary discussions over nearly two decades now. No longer fettered by the primacy of representation, affect invokes that which is impossible to represent. Simultaneously, it is perfectly material: it is a symptom, a bodily state, an image, a musical phrase, or a literary text. Therefore, even if it evades representation, the latter often mediates its existence, even though representation is merely an artistic or thematic elaboration of affect. This is what usually happens. Affect is wrapped in sensation that we share in, in an emotion or a mood that we experience. Representation, therefore, is the shadow that deprives its prime mover of existence. Accordingly, affect leads a secret, clandestine life - by evading representation, it evades meaning altogether. In its translation into meaning, it is a derivative of deceptive representation. Does that not resemble the life of literature itself? Like the affect, literature also proves to be paradoxical: an intensity of perversely constructed representations that defer their meanings. And is not literature, like the affect, something that situates us in the very center of our experience of the world?

Research of the

Polish Academy of Sciences, where he heads the Culture and Literature of Late Modernity Research Group. He recently published a volume, co-edited with Adam Lipszyc, Ciała zdruzgotane, ciała oporne. Lektury afektywne XX wieku (2015). Contact: marek.marzales@ gmail.com 
It is believed that affect is a manifestation of the intensity of existence (after all, inevitably always someone's), a passing from one threshold of intensity to another, something that drives the changeability of our existence. Literary text often makes us excited and is always a place of interaction (Tzvetan Todorov once jokingly remarked that literature is a picnic, with authors supplying the words and readers providing the meanings) - we can say, therefore, that it frequently serves as the proving ground of many a passions. More than once has the picnic slipped into tragedy, jumped in an instant from delight to massacre, funeral, and what have you. Feelings, emotions, experiences, and moods are all merely traces of affects that we - participants of the picnic - have already draped in words equipped with meanings, so the representations expressed in a more or less intelligible manner, thus somewhat petrified or even ossified. The perception of being agitated, aroused, and therefore affected, is only an effect of affect itself - it is our own interpretation of affect, a superficial one and, one might say, skin deep! Meanwhile, our real lives take place elsewhere, as proponents of the psychoanalytical theory of affect claim, placing the wilderness of tangled meanings in the abysmal ardor of the subconscious. Contrary to Spinoza, the father of contemporary affect theory, who claimed that true cognition revealed the origins of affects, the psychoanalysts declare that true cognition is out of our reach. To strive for it - they assert in tandem with contemporary philosophers - is to try and achieve the impossible: affect is essentially unknowable, as it is, according to philosophers, the transcendental condition of the existence of our reality and thus our cognition, too. Affect is an agitation, a purely virtual intensity: what is available of that cognitive excitation is its interpretation from the start. The life and the world around us are streams of affects - we affect and we are affected. Cogito is an illusion, because cognition is becoming. It is thought in motion. If we knew how all things relate to one another, the world could not keep secrets from us; it would become a unified whole (which it de facto is). According to the precepts of Deleuze's post-Spinozan philosophy, when I have knowledge of the balance of power between myself and the world, I am closest to my own fundamental essence, my "thisness," my haecceitas (my "essence," as Deleuze calls it - somewhat deceptively, given the fact that his differentialist inclination would make him rather reluctant to employ traditional essentialist notions). ${ }^{1}$ In that particular moment, I also hold the most power over the intensity of my own existence. The essence is instantaneous (because it is defined by current excitations), and yet eternal, as it virtually participates in the unity of the world, in Spinoza's indivisible Substance. All things remain

1 See Gilles Deleuze, Lecture on Spinoza's Concept of Affect, http://www.gold.ac.uk/media/ deleuze_spinoza_affect.pdf, accessed March 2, 2013. 
somehow related to one another and specific essences are attributed to these relationships. Essences are eternal, but the objects in the relationships are mutable. Therefore, to further expound upon Deleuze, we are dealing with a specific paradox: essence exists beyond time, but its constituent components (its representations) are instantaneous. Eternity and instantaneity are the two sides of essence. They also constitute the modality of affect: each excitation is an experience of essence. Passion as affect is an excitation of essence. Eternity and spontaneity, intensifying and diminishing the force of existence, is a diapason we live in. This is the reason why affect should be considered a transcendental condition of our cognition, a way in which essence ultimately manifests itself. Essences transcend both the subjective state of the conceiving entity and the characteristics of the conceived object. They create "true unity: unity of an immaterial sign [e.g. the sign of a work of art - M.Z.] and of an entirely spiritual meaning." 2 To the question of what is an essence as revealed in the work of art, Deleuze says that it is "the absolute and ultimate Difference," (D, 27) a difference that constitutes being and what allows us to conceive being. Deleuze conflates difference with the figure of "diversity," $(D, 27)$ and thus of virtuality and potentiality. This diversity would constitute the haecceitas of existence. Enigmatically, Deleuze declares that "it is something in a subject, something like the presence of a final quality at the heart of a subject" (D, 28). In an object, in turn, Deleuze identifies it in its representations, in "the way the world appears to us," preferably in works of art. Difference, therefore, is both an individual perspective and an emanation of eternity.

Is this not somewhat familiar? Is not language, in which meanings are established in a game of differences, a matrix of such cognition? Each use of language contributes to its systemic nature, but that nature manifests itself through its use. Not all of these uses, however, are equal. According to Deleuze, literature is an emanation of language wherein essences (and differences) manifest themselves most intensely through individual styles and he expounds upon the subjects in his book Proust and Signs. "If there were no such thing as art, [difference - M.Z.] would remain the eternal secret of each man" $(D, 27)$. Art enables the manifestation of "viewpoints towards a world supposedly the same. [...] Our only windows, our only doors are entirely spiritual; there is no intersubjectivity except an artistic one. [...] Only by art can we emerge from ourselves, can we know what another sees of this universe that is not the same as ours" $(\mathrm{D}, 28)$. "Thanks to art, instead of seeing a single world,

2 Gilles Deleuze, Proust and Signs: The Complete Text, trans. Richard Howard (Minneapolis: University of Minnesota Press, 2014), 27. All subsequent citations in the text will be marked with the letter $D$ followed by the page number. 
our own, we see it multiply, and as many original artists as there are, so many worlds will we have at our disposal" (D, 28); "style is essence itself" (D, 32). "A great novelist is above all an artist who invents unknown or unrecognized affects and brings them to light as the becoming of his characters," claims Deleuze, and then provides examples: "When Emily Brönte traces the bond between Heathcliff and Catherine, she invents a violent affect, like a kinship between two wolves, which above all should not be mistaken for love. When Proust seems to be describing jealousy in such minute detail, he is inventing an affect [...] jealousy being the meaning of signs - affect as semiology."3 The becoming of the world thus becomes a field in which affects manifest themselves.

Deleuze's ideas and metaphors will be explored further in later parts of this essay, but now I would like to use them to examine the writings of Magdalena Tulli as employing the language of affect. Curiously, a lot of things in her writings are happening beyond the field of representation. The world portrayed in the narrative is just decoration for what is taking place behind the scenes and what manifests itself through the organization of representation itself, but eludes straightforward identification and designation. Tulli herself, reflecting on the actions of the narrator from the novel, declares:

From the cracks in the narrative, the contradictions, the derailed logic of his argument, stares a somewhat understated statement. The author seems to be trying to communicate with the reader behind the narrator's back. ${ }^{4}$

This means that in the work of Tulli diegesis is much more important than mimesis and the rhetorical (and the affective) is more important than the referential. Contrary to most novelists, Tulli saddles her readers with a significant burden. The author eagerly engages in ironic parabases: she peeks out from behind the world as it is portrayed by the narrator, commenting on the unfolding of the events in the narrative and the decisions of the characters. It is then up to the reader to reconstruct the world concealed by the facade of decorations arranged in this particular manner. Tulli's non-fictional fictions are often read as parables, and her critics - as if unaware of the evolution that the novel has gone through over the course of the twentieth century - claim that her work is deficient in realism, engages in excessive metaphorization of fictional

3 Gilles Deleuze, Félix Guattari, What is Philosophy?, trans. by Hugh Tomlinson and Graham Burchell (Columbia University Press, 1994), 174-175.

4 Marek Zaleski, "Za plecami narratora. Z Magdaleną Tulli rozmawia Marek Zaleski," Res Publica Nowa 5-6 (1999): 81. 
events, and treats characters in a pretextual manner, reducing them to mere puppets. ${ }^{5}$ Even if that is true, then everything still unfolds according to the author's designs. The literary machinery that Tulli sets in motion toils to serve affect. How do we define affect here? Succinctly put, it is something that initiates the becoming of the novel's fictional world. What is it in this particular instance? Well, it is fairly hard to define because, as affects are prone to be, it is an event to which the law of noncontradiction does not apply. It is an upheaval of the semantic structure, something that gets lost when rendered not only into meanings, but also into emotions and feelings. It is an imposing intensity out of which representations and their meanings arise. It is virtually the blank tile in Scrabble: without it, meaning would fail to constitute itself, but the tile itself is only a medium for what can just as well be another, different meaning. ${ }^{6}$ In that particular sense, affect is semantically blank (referencing Deleuze, Mieke Bal describes it as a "semantically void intensity": it can be experienced and diagnosed only in consequence of our emotional reaction to it). ${ }^{7}$ It exists through representation (although simultaneously it exists beyond it). It is our subjectivity, emanating as receptiveness towards the world affecting us, and a readiness to embrace meanings, pulling meanings into existence. Therefore meanings and emotions always belong to someone, and are rarely final, often disorienting. Were they final, rather than fleeting and mutable, they would have had no capacity to nurture life (which, as we may recall, is a stream of affects) and would situate themselves in the sphere of entropy and death, in the world of definite identity.

What then is Tulli's fictional world based upon? The feeling of lack, ${ }^{8}$ the uncertainty as to how to interpret the desires of the Other which, as we know, breed fear, a primary affect according to Lacan. This lack then emerges as the ontological foundation of the subject's world. Thus, fear becomes a ubiquitous

5 Only her most recent collection of short stories, Włoskie szpilki [Italian Pins] (Warszawa: Wydawnictwo Nisza, 2011), containing strong autobiographical references, breaks although not fully - with her prior methods of constructing the world portrayed in the narrative.

6 The problem is that, in light of the affect theory, in the game that the world plays with us all the tiles we are dealt are originally blank.

7 Mieke Bal, Affect as Cultural Force, 2 (text submitted to the seminar of the Culture and Literature of Late Modernity Research Group held in Warsaw, October 15, 2013).

8 Tulli explains the reasons for her writing thusly: "The world is choking with a sense of lack. The experience of lack is maybe the only thing that touches the poor and rich, the tormentor and the tormented, equally. Lack stimulates desire. Quenching one's desires never really brings satisfaction, a new lack always surfaces, thus the ever-present suffering. Stories of lack play a leading role in In Red [W czerwieni]." Zaleski, "Za plecami," 81. 
affect, one that trails our every effort and endeavor like a shadow. In Tulli's writing, this lack takes many forms. It is the oppressive strangeness of the world and the pervasive desire for it to make sense. In turn, the desires of the subject can also be understood negatively, as a sort of lack, if we were to adhere to Freud's suggestion that desire stems from the unconscious, a drive which itself is a function of need. Therefore quenching a desire has to entail abolishing some lack. The desire to eliminate a lack of meaning is the hardest to quench: according to Lacan's known precept, in the signifying chain, the signified continually slides beneath the signifier. Dreams and Stones, Tulli's story about the rise and fall of a world-city concludes with a somber hymn to the "void," "a steadfast endurance free of any name." 9 In this narrative illustrating the fate of a gnostic desire to build a perfect world, as soon as something is no longer free of a name, it becomes immediately lost in the unceasing scramble for meaning. The reality of Sny i kamienie [Dreams and Stones] incorporates a specific nominalism: it is not bound by the laws of physics or other laws. The incredible feats of engineering and urban planning on display are merely a hoax, and in the end, rhetoric is revealed to be the only undisputed field of expertise, the world portrayed in the book demarcated only by the limits of language. Language manufactures artificial nature, either friendly or not. The existence of everything is mediated through words, claims the narrator, and the "soul" of every word is elusive in the differences of meanings, as each meaning has a counter-meaning (in the universe of Dreams and Stones, the template can be found, for example, in the tree of life and the "anti-tree," and the city and "counter-city"). In the "everlasting, nameless constancy" affirmed by the narrator, there is an undertone of relief, a relief with which the narrator casts aside dreams about a world of final shapes and meanings. She conflates the world with constancy, which is neither apathy nor surrender.

Fear and desire are two sides of the same coin, namely, lack. Lack stimulates desire, which in this case are the dreams of the denizens and their wish to create a new, perfect world. The eponymous stones - figures of perfection and the unambiguity of existence, things in and of themselves - are beyond our reach. In the end, the once wonderful structure is corroded by the dreams of the denizens themselves, by loci of disorder, carriers of doubt, phantasms of uncontrollable yearning: the city will slowly turn to ruin, collapse under the unceasing onslaught of the counter-city and antinomies forces of chaos, corrupting everything in their path. Let us reject the desire for perfection, Tulli seems to say. Let us approach life as a compromise, as a clash of forces

9 See Magdalena Tulli, Dreams and Stones [Sny i kamienie, 1999], trans. Bill Johnson (New York: Archipelago Books, 2004), 110. This essay may feature fragments of my prior reviews of Tulli's novels. 
traveling along infinitely different vectors. Let us no longer dream of perfect creation, let us trust, instead, in constancy - only then will we avert a new Deluge "bring everyone, including those already on the bottom, safely back home," says the narrator. However, contrary to the assumptions inscribed in this prose, it also seems to paradoxically imply the following: let us abandon fear, because as living humans we are affected, and given that affect is essence, then we always participate in our own essence - we are always a part of the world. And we always get only as much essence as we are entitled to. We never lack for anything! ${ }^{10}$ The eponymous stones, embodiments of perfection and the unambiguity of existence, and the monumental Socialist Realist reliefs on the Palace of Culture and Science (to which the author alludes to) are a parody of our contemporary notions of the ultimate. What we are dealing with here is also a parody of Le Corbusier's vision of the city as the ultimate "machine for living," with a disavowal of the utopia offered by socialist mythology. Tulli seems to be ridiculing the dreams of philosophers and politicians. In accordance with the engineers behind the perpetuum mobile, the world of Dreams and Stones is virtually a bodily organism and machine, whereas affect is a manifestation of vitality (and freedom). The experience of one's life is involuntary and recorded in one's body. Our bodies are smarter than us and know what facilitates our self-preservation. In the philosophy of affects, the body is understood much more broadly than just in the literal sense: this philosophy presumes the multiplicity of polymorphic elements constituting the Being, that is, the Spinozan substance which is an ontological continuum that entails the irresolvability of immanence and transcendence, and a lack of distinction between the physical and the mental, the vital and the superhuman or metaphysical. In their writings, philosophers involved with diagnosing the postmodern condition often describe the world as both a biological subject - as pure life, a living organism governed by the economy of desires and a social subject transcending biological determinants - a construct produced by culture, a machine regulating our behaviors and steering our desires. "Contrary to normal self-regulation (rule of self-preservation), society is "both machine and organism," that is, both the subject of social regulation (culture) as well as its object - it is this wish to become a machine [a selfregulating mechanism - M.Z.] that likens it to a bodily organism."11 Thus, the affective economy, perceptible in the approach to the social dimension that transcends the individual - the dimension in which the unconscious is entangled - becomes extremely significant. The city from Dreams and Stones,

10 That is the interpretation Deleuze uses in his lectures on Spinoza's concept of affect.

11 Georges Canguilhem, The Normal and the Pathologic (New York: Zone Book, 1991), 252. 
filled with desire, resembles a Deleuzian "desiring-megamachine," a factory of the unconscious. In Anti-Edipus, Deleuze and Guattari speak of a more "machine-like" character of the unconscious. ${ }^{12}$ The machinism present in the production of desires - in the production of dreams and phantasms; the world as a factory of desires, as a device regulating the stealthy passage of desire, is something that is very evident in Tulli's writing. As is the diagnosis that the social and political are the territory of desire. The diagnosis, expressed somewhat metaphorically in her first book, will be brought fully into the open in her novel Wtoskie szpilki [Italian Stilettos], fiercely evident in the clearly autobiographical order. In that book, school is a totalitarian institution and a metaphor for the lives of Poles in the Cold War era, but even more than that, it is a landscape in which to work through grief for the childhood of which the author was deprived. In Dreams and Stones, the city is a grand infrastructure of the desires of its denizens. In Tulli's novel In Red [W czerwieni], the flow of desires is regulated by the "flow of desires and liabilities."13 This particular novel (and the author's subsequent efforts) can be examined perfectly well by instruments put forth by Eva Illouz in her analyses of emotional life under capitalism. ${ }^{14}$ In In Red, the puppet-like nature of the characters is fully intentional: for someone deprived of access to the Self, and as such cut off from one's own feelings, others - even loved ones - become social figures, symbolic signs, rather than something real. These suppressed emotions finally surface and when they do, they do so as destructive forces. Is it because desire stands in opposition to the social order and is revolutionary in nature? In the novel, the phantasmal and the material propel and drive each other: trapped by matter as products to be consumed, the desires of the denizens of the phantasmal Ściegi [Stitchings], a seaside city under Swedish control, turn into fetishes. Fantasy becomes the medium for the experience of pleasure and for emotions institutionalized in the violent practices of manufacturers and consumers, the rituals that alienate us from life and lead us towards catastrophe: the suppressed eventually returns and demands redress. On the other hand, Skaza [Flaw] may be read as a story about the rise of an authoritarian society as a "desiring machine." Here is a city somewhere in Europe and a handful of its citizens - the realities are just a sham, a piece of stage decoration. Life

12 See Michał Herer, Gilles Deleuze. Struktury - maszyny - kreacje (Kraków: Universitas, 2006), 101.

13 Magdalena Tulli, In Red [W czerwieni, 1998], trans. Bill Johnson (New York: Archipelago Books, 2011), 11.

14 Eva Illouz, Cold Intimacies: The Making of Emotional Capitalism (London: Polity Press, 2007). 
goes on as normal until one day a crane cable snaps and sends a heavy, fireproof safe tumbling down to the ground, causing catastrophic consequences: first, a stock market crash, then an armed coup which caused an outburst of revolutionary fervor, and finally the establishment of a dictatorship. Obviously, all the contents of the safe - valuables, securities, bonds - disappear in the turmoil. Everything that seemed durable, indestructible, vanishes into thin air. City squares begin to fill with refugees who are victims of forced resettlements stemming from the ever-deepening political crisis. It is not difficult to surmise that they will turn out to be the real victims of the fracas. Tulli dramatizes the narrative, while retaining its laconic character, perfectly portraying the mood that accompanies the spread and escalation of violence, itself always courting the strongest actor. It portrays the degree of egoism that always drives the self-serving defense of one's possessions, the mechanisms of servile cynicism, the stigmatization of scapegoats, and the establishment of a new order of ranks and relationships across a world sliding into barbarianism which still feverishly keeps up appearances of order and the rule of law. Her narrative also reveals the frailty of bodies not wearing uniforms and bereft of other respect-commanding garbs. Her novel joins the ranks of many books dealing with the rise of fascism. The novel's narrator confesses a deep, sympathetic kinship with a world that time and time again slips from her control, a world that exists as a continuum, a world in which the line between fiction and reality is arbitrary - both are simply different attributes of one matter. The narrator of Flaw states:

From a certain point of view there are no made-up stories. Towards the end, all appearances to the contrary, each one turns out to be true and inevitable. Each one is a matter of life and death. Anyone who spends time in its unseen back area has to accept all the shared and ownerless pain it contains, spilling this way and that - because the channels through which it flows are all connected. ${ }^{15}$

The ambiguous and sometimes sinister effortlessness of creating worlds puts the heaviest of burdens on the writer's shoulders: she has to take responsibility for her own actions, as well as for her point of view and the style in which she manifests herself. The narrator's compassion and empathy for the victims are an expression of sympathy for those who - as we keenly believe - have brought this all on themselves, those without whom "the world will be better off." In any case, in the fictional world (and the non-fictional, too), compassion is exposed to the dialectic of chance and necessity (more on that in a moment)

15 Magdalena Tulli, Flaw, trans. Bill Johnson (New York: Archipelago Books, 2007), 160-161. 
fraught with consequences for those living inside the narrative. That is why the ending will read: "Happy endings are never happier than possible."

We often read that Deleuze and Guattari juxtapose Freud's concept of the "theater of the unconscious" with their own, which perceives the unconscious as a machine, a factory of the impersonal, the universal, that which is exposed to the violence of signs unrestrained by the ostensibly self-transparent subject. Tulli's work employs both of these approaches. In Moving Parts, she extensively uses circus metaphors, whereas in Flaw, the narrative starts backstage in a theater, a factory of reality tainted by the provisionality and mediocrity of the entities that exist within it. This is a world of appearances and charades: there is no "depth" to it. All depth is "pure illusion - paint and plywood, nothing more." In this world, all power is usurpation, rooted in partial and substitute desires, masking only lack, the feeling of emptiness burrowed in the "marshalling yards," always available and always scornfully indifferent toward our concerns. The narrator is no longer the grandiose director. Instead, the role of demiurge is now delegated to the eternally dissatisfied "contractors," maintenance personnel for the main installations and the rest of the equipment that a functioning stage requires, the "fallen angels of the back areas": "the denim-clad workers," stage hands, backstage interns, and the tailor (the entire story starts with a paean to the "art of the dressing room" which quickly devolves into a resigned apologia for people working "the invisible back area"). All these people have true, although cynical, knowledge of the world. What they do not have, however, is the full extent of power. "The true nature of the highest authority is permanent absence," we read in the end of Flaw. Power is held by the impersonal (the resultant of desire) which manifests itself in clashing narratives, constantly shifting from one to the other and slipping from the narrator's control. What is the ubiquity of narrative? In Moving Parts, her earlier novel, Tulli has already disclosed the driving force that propels the machinery of the world of the novel. The world is neither meaningful, nor absurd. It simply is - that is all. And such as it is, it amazes, delights, bores, and frightens us. But whenever we try to understand it, it escapes our grasp, leaving only decorations where reality once was. Why? Because it appears to us in the form of a narrative, along with its need for rationality, for cause and effect, a narrative making use of the symbols that make the world our home. This particular narrative perspective has had great success in the humanities. Emil Cioran once wrote that nowadays we are, all of us, potential writers, just like everyone was a potential theologian in the Middle Ages. The author of Moving Parts makes the world unfamiliar rather than familiar. She demonstrates the sort of misunderstandings that may stem when "a tale someone has nonchalantly conjured up must suffice for the entire substance of somebody's existence," a tale "hungry for subjects and predicates, lodged 
in their tissue like a rare species of rapacious parasite."16 She displays how words become the suffering flesh, how a trivial story that starts to control the lives of fictional characters "confined by the circus metaphor in which their fates are enclosed" suddenly transforms into reality, with all its sinister consequences - that is into history.

Who is the narrator in this story? The novel's "Narrator," who becomes a character in Moving Parts - "a short tale of betrayal" - is merely a ridiculed figurehead, entitled to nothing more than a "scrap of existence." History unfolds , "behind his back," "between the lines, in the dark corners behind the paragraphs." And we also do not know anything about someone who called the narrator into being, he/she remains impersonal, devoid of psychology or any semblance of an inner life (like the other characters). He/she is - that is all. He/she can only speak, reveal new complications, peek into "expanses of possibilities that will never be fully explored." He is no supreme authority. He is also the void, filled by the "volatile essence of longing" for representation, the rampant element of the novel. The narrator struggles with a trivial story of marital infidelity, but the story is a treatise on the world's lack of transparency, where narrative is the highest and most unreliable instance of truth, because in this case the eponymous "moving parts" are the true driving force, as is the language with all its endowments, in which figures of speech, akin to railroad switches, unexpectedly shift the direction in which the narrative is heading, up until the very end, when the circus metaphor invalidates all the efforts of the narrator who struggles to rescue the fictional world. We can even go so far as to say that Tulli's text is a Deleuzian "literary machine"17 that subjects the reader to the violence of signs. A lack-driven affective machine that produces literary effects.

By competing with each other, tales or "simple stories" - as the author herself ironically calls them - transform our lives into either a series of charming events or a spectacle of pain and misery. This fluctuation and ambivalence serves as a guarantee of the world's wonder, but is also a source of its inherent flaw. The stoicism ingrained in such a vision of the world strongly resembles Spinoza's mechanism which,

is based on the belief that no things or events have objective moral and aesthetic values, that no thing is good or evil, beautiful or ugly, in and of itself. We can call something good or bad only in view of man, whose needs are the only source of moral judgement. [...] We are to

Magdalena Tulli, Moving Parts, trans. Bill Johnson (New York: Archipelago Books), 8. 
consider good and evil all things that either facilitate or hamper our cognition, respectively. ${ }^{\mathbf{1 8}}$

Good affects empower the agency of our existence, bad affects disempower it. Thus, in the words of Samuel Johnson, "the only end of writing is to enable the readers better to enjoy life or better to endure it." Each of us, however, has an individual threshold of intensity, as do all the things around us, and it is through intensity that our relationship with the world and its essences manifests itself. In Flaw, Tulli's narrative unfolds from the perspectives of individual characters. We hear the repetitive choruses of: "If I am a student...," "a notary," "a servant," “a policeman," “a newspaperman," "a tram driver," “a tenant gazing from behind the curtain," "a denim-clad man," "a prematurely born baby," "And if this is my story, then...," etc. Does that not affirm the "individuating viewpoint superior to the individuals themselves" $(D, 105)$ which - if we were to believe the philosopher - is equal to essence itself? Each individual essence is an intensive quality and each object, including each and every one of us, comprises a conglomerate of a range of different intensities which constitute the essence. According to Deleuze, each representation essentially drives towards the epiphany of said intensities. "Combray is the essence," writes Deleuze. It is the "individuating viewpoint," it [the essence - M.Z.] "has the power [...] to remind us, however intensely, of the self" and "every 'explication' of something in this sense is the resurrection of a self" (D, 120). In a somewhat similar manner, Joyce portrayed literary work as an epiphanyproducing machine. Deleuze references the author of Ulysses in his book, too $(\mathrm{D}, 123)$. How does this manifest itself in Tulli's work and what aims does it serve? I will start with an attempt to answer the second part of the question. It serves to remind us of the importance of the discovery that narrative - the "trivial story" - assists us as a structure through which to understand the world and a script for our actions, that it provides us with a place where we can manifest ideas we hold dear. Each fact, even facts of nature, is available to us only through someone else's narrative that describes it. Thereby, it implies patterns of fictionalization - explication and placement within the context of other facts. By obscuring with words, the "trivial story" steers our understanding and interpretations of the world. And given that there are no pure occurrences, just someone else's interpretation of them, all of our declarations about the world are only a fragment of our autobiography - if so, then the question of our responsibility for our ideas and the "stories" we produce comes back to haunt us. In the meantime, the squares keep filling with refugees

18 Leszek Kołakowski, introduction to Etyka, by Baruch Spinoza (Warszawa: PWN, 1954), XXXVIII. 
and "the plots they bring with them." The back areas - invisible yet never silent - are the "marshalling yards" of the stage on which everything seems to take place, is a storeroom for set decorations, narrative clichés and metaphors that exert a great deal of influence over what is happening on the stage. There is a little bit of Lacan's "Big Other" in the "back area"; a desiring machine over the desires of which we have absolutely no control. On the contrary, we are subject to its incomprehensible mechanics - thus our anxiety; being free from our fear means being free from being dependent on someone else's desire. The latter disturbs us, as it has to do with the presence of the Real which frightens us. And rightly so: we read that "back area has no room for pity or compassion." Installed by accident in the back area of the fictional world, fragments of old decorations for stories about the "difficulties of life under the oppressive regime" begin to steer reality and decide the fates of refugees.

Tulli's books deal with the anguish of existence. Explaining the decision of the Gryfia Prize jury, Inga Iwasiów stated: "We award the Gryfia Prize to Magdalena Tulli, because Włoskie szpilki is a painful experience."19 That is true, it is painful because the book deals with the ghosts of childhood. Our childhood, which gilds our memories, often seems to us a land of lost happiness. But that is rarely true in Tulli's novels. Here, childhood is a menace. The narrator of Tulli's stories shares the fate of those who are also children of Holocaust survivors. Her life resembles the life of the narrator of Art Spiegelman's Maus - like him, just like he was an inadvertent victim of his father, a Holocaust survivor, she is the victim of her mother, a former Auschwitz inmate. The cold, elegant prose of Włoskie szpilki is a way for the author to work through the grief of losing her mother and, to an even greater degree, the grief of being deprived of her childhood. The book is an attempt at coping with inherited trauma, with fears that morph into new idiosyncrasies. In this particular case, irony seems to be a medicine one swallows to cross the minefield of one's own wounded memory without incident. The narrator, a mother to two adolescent sons, is held hostage by that little girl. She feels a kinship with the child, but helping her - unlike helping herself - is simply beyond her means. Once again we are dealing here with the true claim that the child is the parent to the adult. Therefore, if it is plausible to say that we are dealing with affects in the case of Tulli, then it is due to the way she constructs the narrative, that is, on account of her specific style. What, then, is its secret? Well, it lies with its affective qualities: "a tale someone has nonchalantly conjured up must suffice for the entire substance of his existence." But the emotional affect is a product of using the rule as it is visible at the level of a sentence, a paragraph, finally the entire text: it is in the transition, the transfer of meanings

19 See http://www.instytutksiazki.pl/pl,ik,site,6,4,27518.php, accessed March 3, 2013. 
(and the resulting transfer of emotions) specific to the affect inside the body of the text, the juxtaposition combining the irreconcilable or contradictory in terms of type and content. The text is imbued with "affective syntax."20 The narrator of Moving Parts, "in a foolish pursuit of runaway story," struggles with the narrative. From behind her back peeks the anonymous author, to tell us about the exploits of the narrator and her character traits. This ironic paralysis communicates to the reader that we are all playthings of fate. The reader also shares in the desperation of the narrator. Like him, the reader "begins to question, whether a circus farce can bear the weight of what was to be conveyed here." What the narrative manages to say, however, forms a profound diagnosis of the narrator's - and the reader's - condition, and the truth of this condition is experienced in the reading about the adventures of the puppet-like characters:

While they remain at the table they look happy; a thoroughly secure future extends before them: in the morning coffee and rolls, in the evening somersaults over the abyss, and so on for all eternity. Is this enough to make them feel confined by the circus metaphor in which their fate is enclosed? And even if so, do they have any course of action other than to take up the life that has been assigned them in this tale? Perhaps it would be better for them to remain forever at the table set for breakfast, she with a cigarette, he with coffee cup in hand, and between them on the white tablecloth, let's say, a green apple, which somehow neither of them feels like eating. They'd sit like that endlessly, sprawling on padded chairs whose softness comes from the pink stuffing hidden under the upholstery. It isn't difficult to imagine what hardships, mortifications, and disappointments these two would be spared. But no one wishes to remain forever in an inconsequential moment. Thoughts flee from it in reverse gear toward accomplished facts, while desires, having nothing to look for in the past, rush forward at breakneck speed. Only the second hand of a watch trashes about in the present tense, trembling nervously. All alone, over and again it passes by the two broader hands as they turn unhurriedly in their matching orbits, evidently connected with them only mechanically. The rhythm of its feverish twitching is foreign to them. To the body though it is only too familiar - the delicate body, warm with desires, which, surging toward the future, at that very moment collapses into the past, sinking helplessly into it, enmired. And while the moment called the present still continues, its existence is felt merely as un uncontrolled turmoil of heart

20 This term was used by Mieke Bal in the above-mentioned lecture, to describe the way in which exhibits in art galleries are designed nowadays. 
and mind, a chaos from which one tries to flee as far as possible. And so the dining room will soon empty and the pair finishing their breakfast will eventually vacate their chairs, abandoning green apple peelings and the crumbs scattered over the tablecloth. (Tulli, Moving Parts, 12-13)

This excerpt encapsulates the event-production of existence. In the now of the present moment, we are situated between expectation and fulfilment. Each moment is a maelstrom of what is, an explosion in which something happens but quickly fizzles out, leaving behind only traces of what it was; and given that we live within the horizon of expectation, this something also conceives of what will be. And in the meantime, something completely different finally takes place! The long quote is also a fine illustration of how predicates operate in Tulli's writing. The dynamics of the narrative, driven here by something more than just the need to put one sentence after another, make the world portrayed in Moving Parts a rowdy adventure, where the course of events is determined by the rhythm of the rhetoric perpetual mobile toiling in the service of unbridled imagination:

Let's say that it is still raining. Let lights be reflected in the wet asphalt as if it were a mirror; let clouds pass across the puddles, and in the aquaria of the shop windows let umbrellas rise, weightless as jellyfish. The raindrops have already added a spotted design to the plain fabric of the man's jacket. Let's say that his overcoat was stolen at the airport. Did he also lose his wallet, tucked into the inside pocket? The wet sidewalk reflected the lights of the hotel, while the semitransparent image of the bronze rider shook slightly in the glass of the revolving door and spun on his horse as if on a merry-go-round when the new character entered the lobby. Across the mirrors drifted the aforementioned jacket, an immaculate white shirt collar and a necktie that is rather ironic, but also rather flashy - of course, within the limits, of what's permissible in places where the only salvation is to reconcile freedom with servitude. (Moving Parts, 16-17)

In Flaw, we read: "up until now, no story has managed to be played out properly to its conclusion": the story, "derailed from its course," falls into the inevitable "track of the world, always ready to give direction to whatever is moving without a purpose or destnation" - is not such a direction of the narrative alienating? At best, it releases a very anxious curiosity. But Tulli's stories require something more from the reader. Ever since the events atop Mount Moriah, the human condition has been one of victimhood, but the twentieth century has made that metaphor more or less universal. Tulli's stories appeal 
to the solidarity we feel towards the victims - they are the ones symbolizing the naked truth of life in this instance:

an existence that serves no worthwhile purpose but merely pays homage to the chaos of the transformations of material, the perpetual circulation of hope and despair, and in no respect, either figurative or literal, fulfills the requirements of orderliness. ${ }^{21}$

The affective in representation, according to Deleuze or Massumi, stems from the rift between the meaning sealed into it and the effect it produces. Affect, or intensity, is the lack of a relationship between content and effect. It does not depend on the signified. Intensity belongs to the unconscious, it is its vestige in the representation. It exists outside discourse, between expectation and fulfillment - narratively without place. Emotional qualification is a symbolic rendering of intensity, reducing it to only one of many forms of expression. Intensity releases the swell of the narrative sequence, its flows regulate the course of the narrative - like they do in the "blooming" progression of affective syntax in Tulli's writing. Here is Stefania, killing time with cross-stitching after being dumped by her fiancé:

The dark red blossomed upon the tambour and brought sudden confusion among the lilies. The design looked as if it had been stained. Stefania was frightened by the rose, which had escaped from under her dexterous fingers. Her cheeks burning feverishly, she unpicked the silk threads. Gusts of air swept them up and carried them all over the world. Obedient to electrostatic forces, the threads settled on the roofs of military trains and on uniforms. Every man on whom a scrap of red silk thread came to

21 Magdalena Tulli, Flaw, 156. Tulli never locates her metaphors in a final, specific place in history: the denizens of her city believe "rumors about (...) landing by the allies to bring liberation; now it was Kolchak's forces, which somewhere out in the world would occupy the capital before suppertime and reinstate the legitimate government; now it was a band of partisans, armed to the teeth and promising to save the country from anarchy; now an international peacekeeping force was going to intervene and persuade the dictatorship to step down; now it was the arrival of Huns, after whose passage not one stone would be left upon a stone." (ibid., 128) Victims of the coup may be either Kurds or Kosovar Albanians: it is about purging the "other," forever relegated from mankind. The attitudes of the citizens towards these others, and numerous allusions in the text itself, suggest that they are to suffer the fate of the Jews, condemned to mass slaughter, although the word "Jew" is never once uttered in the entire novel. The author, however, leaves no room for doubt: "The details of this affair, the question of the unaccountable disappearance of so many people at once, baffled the minds of all those who attempted to fathom it" (ibid., 164). 
rest was struck by a bullet in the war. Before Stefania had finished the sachet adorned with lilies, Kazimierz returned on a train, free of cares, with a red thread tangled in his hair, in a long box fastened with nails. The casket was buried in the town cemetery in the sector containing the graves of army officers; the salute rang out and came back as an echo. And that was an end of it. In the meantime the roof over Colonel Ahlberg's quarters was still leaking, and after successive attempts at repair the wretched pail had to be emptied even more often than before. ${ }^{22}$

It may even be said that Tulli's writing, at the syntactic level of narrative events, resembles the work of Polish avant-garde poet of the twenties, Tadeusz Peiper, and his "blooming sentences,"23 given the cuts that happen after each fictional episode. Each subsequent sequence or paragraph seems to be another small catastrophe, an excess, an unexpected turn of events, an interruption of the past's transformation into the future. An event that plays out along the expectation-fulfillment vector, and turns out to be a surprise. Thus my earlier claim, that it resembles a railroad crossing, with switches controlling the movement of meanings. This shift, resulting in a "transition" in our reading, a movement of constituting meanings, is what being affected by a text is like. The affect is the "passage", says Deleuze. It is a transfer of intensities, a becoming of emotions shared by the reader, emotions transmitted in textual representation.

The books that Tulli offers us (it is telling that each subsequent edition includes changes) pursue essences, pursue the haecceitas of frail configurations, the intensity of the stream of life, the latter a "fever of desires and disappointments" that unfolds ever onwards, aimless and directionless, always obscured by someone else's - although always victorious - narratives, conceived by minds trying to shape what is essentially suspended in perpetual motion (like the blank tile in "Scrabble"). Which is nothing else than a desperate attempt at finding an answer to the desires of the Other. Tulli's sentences document the transition from intensity of experience to its expression - a record of the troublesome burden of belonging to a world stretched between lack, pain, and desire. ${ }^{24}$

Translation:Jan Szelagiewicz

22 Magdalena Tulli, In Red, 32.

23 "The blooming sentence produces in its course the alternations of different stages of crystallization of the same ingredient," Janusz Sławiński, Koncepcja języka awangardy krakowskiej (Kraków: Universitas, 1998), 127.

24 As we can recall, "there are no fictional stories [...] If this is my story, I am forced to negotiate, to accede to humiliating compromises, to make concessions, without losing hope," Magdalena Tulli, Flaw, 160. 